\title{
A Comprehensive Exploration of Pharmacological Properties, Bioactivities And Inhibitory Potentiality of Luteolin From Tridax Procumbens As Anticancer Drug By In-Silico Approach
}

\section{Shradha Lakhera}

Uttarakhand Open University

Meenakshi Rana ( $\Delta$ mrana@uou.ac.in )

Uttarakhand Open University

Kamal Devlal

Uttarakhand Open University

Ismail Celik

Erciyes University: Erciyes Universitesi

\section{Rohitash Yadav}

AlIMS: All India Institute of Medical Sciences

\section{Research Article}

Keywords: DFT analysis, Molecular Docking, Molecular Dynamics simulations, MCM7

Posted Date: November 2nd, 2021

DOI: https://doi.org/10.21203/rs.3.rs-974470/v1

License: @ (1) This work is licensed under a Creative Commons Attribution 4.0 International License. Read Full License

Version of Record: A version of this preprint was published at Structural Chemistry on January 28th, 2022. See the published version at https://doi.org/10.1007/s11224-022-01882-7. 


\section{Abstract}

Tridax procumbens is a flowering plant of the Asteraceae family with a wide range of medicinal uses like antiinflammatory, anti-diabetic, anti-microbial, immunomodulatory, etc. This study aimed to investigate the anticancerous activity of human lung cancer for targeting Luteolin, a phytochemical of Tridax procumbens. The computational study has been done for studying the structural properties of Luteolin. The drug-likeness of the molecule has been predicted by virtual screening of ADMET properties. The molecular docking technique of the in-silico method is performed to check the complex formation between protein and ligand. The reactivity and stability of the molecule are investigated with the help of molecular dynamics (MD) simulations. In the present work, we have tried to establish a strong candidature of any of the phytochemical of Feverfew as an inhibitor against human lung cancer.

\section{Highlights}

1. Prediction of hindrance of phytoconstituents of Tridax Procumbens on MCM7 cancer.

2. Holistic approach of Luteolin to avenge against MCM7 human cancer.

3. ADMET profile of Luteolin predicted to be safe with no toxicity.

4. Chemical reactivity states the chemical reactivity of Luteolin.

5. In-silico study predict inhibition effect of Luteolin against MCM7 human cancer.

\section{Introduction}

Cancer is one of the deadly diseases present in our world that majorly imparts in the global death ratio yet it is incurable. It can be defined as the process of abnormal and uncontrolled cell division that occurs inside the human body and invade other parts, destroying body tissues [1]. It can affect any organ like the lung, kidney, intestine, uterus, brain, and even blood [2]. World health organization (WHO) has reported 9.6 million deaths, or one in six deaths, in 2018 and stated that cancer is the second leading cause of death worldwide [3]. The Globocan report 2020 issued by WHO reported that lung cancer is the second disease imparting $11.4 \%$ of the total cancer cases after breast cancer (11.7\%) [4]. Lung cancer has the highest mortality rate of 2.21 million cases of the total deaths recorded from cancer in 2020 [4]. The dysregulation of Deoxyribose Nucleic Acid (DNA) is the major reason for cancer initiation and progression in the human body [5]. Minichromosome maintenance (MCM) complex is the fifth most common type of cancer that leads to the evolution of the prereplication process for DNA [6]. The regulation of MCM protein in the human body leads to the proliferation of various types of cancers [7]. MCM7 plays a vital role in cancer development and progression and acts as an initiator in eukaryotic DNA and G1/S cell cycle propagation [8]. It is one among the family of MCM DNA helicase comprising of six conserved proteins called MCM2-7 [9]. It was first isolated from Saccharomyces cerevisiae (budding yeast) [10]. This process is called DNA replication licensing in which the MCM complex unwinds the bounded strands of the DNA [11]. This unwinding leads to genome duplication in proliferating cells and chromosomal defects. Such chromosomal defects result in tumorigenesis [12]. MCM proteins are found to be highly involved in human cancer evolution and malignant transformations. Thus, the MCM proteins are considered promising targets for cancer drug development. 
On the other hand, in the last few decades, medicinal herbs have been shifted from fringe to mainstream use and a more number of people seek remedies in herbal extracts $[13,14]$. Plants have always been an important source of anti-cancerous supplements. Natural extracts share a large part in anticancer drugs available in the markets. Many studies have been reported for anti-cancer ailments from herbal extracts like gedunin for ovarian cancer [15], ginsenoside for breast cancer [16], cinnamon [17], and many more. These findings have motivated us to work specifically on herbal extracts. For the present work, we have considered a tropical plant Tridax procumbens. This plant has historical shreds of evidence for being used as a medicinal plant [18]. The plant is native to Asia, America, Africa and, Australia. In many countries, Tridax procumbens is widely used for the healing of open wounds [18]. This herb is also known for its wide range of pharmacological activities like antifungal [19], anti-inflammatory [20], anti-tubercular [21], hepatoprotective [22], anti-diabetic [23] etc. It is also known for curing asthma [24] and is a fulfilled herb with secondary metabolites like steroids, terpenoids, tannins, flavonoids, saponins, glycosides, and amino acids [25].

The virtual screening of pharmacological properties is done for Luteolin to study its druglike resemblances. The energy optimization of the structure of Luteolin is done to investigate its stability. The binding of ligand to protein is accounted by performing molecular docking and the stability of the complex formed by docking of protein and ligand is verified by performing the molecular dynamics simulations. In the present paper, an insilico study done with Luteolin as an inhibitor will help in establishing the strong candidature of Luteolin as a potential drug against human cancer.

\section{Material And Methods}

\subsection{Potential target protein structure for cancer MCM7 protease}

Human cancer encodes a large number of protein structures. The structure we have considered for this study is

protease MCM7 (PDB ID: 6XTX, resolution: $3.29 \AA$ ). MCM7 can metastasize and destroy the living tissues in the body. The malignancies in which MCM7 is involved are hepatocellular carcinoma, head, and neck, esophagus, etc. [26]. Thus, it is suitable to design a study that will identify the compound with inhibitor activity for preventing replication of DNA of cancerous cells. 3D structure of protein MCM7 is downloaded from "Protein Data Bank". Removal of heteroatoms, water molecules, and addition of polar hydrogens is done with the help of the software "BIOVIA Discovery Studio Visualizer" (https://discover.3ds.com/discovery-studio-visualizerdownload). The structure of receptor protease MCM7 with DNA backbone and basic pairs located at the center of the structure is shown in Figure 1.

\subsection{Potential inhibitor: Tridax procumbens}

Tridax procumbens is a phytochemical-rich plant constituting Baicalin, Tetrandrine, Luteolin, Apigenin, Stigmasterol, Catechin, Epicatechin, Quercetin, Myricetin, Gallocatechin, Sitosterol, Akuammidine, Kaempferol, and many more [27]. Among all the phytochemicals, Luteolin is a flavonoid having anti-cancerous properties [28]. Numerous works have been done so far reporting the anticancer properties of Luteolin [29]. Anticancer activity of Luteolin is investigated against gastric cancers [30], breast cancer [31], prostate cancer [32], brain tumors [33], cervical cancer [34], skin cancer [35], etc. Thus, it makes sure that our vision to use it as an anticancer agent will not disappoint us. Luteolin is a flavonoid belonging to the Vitamin B family. It is mainly 
present in many food supplements like parsley, broccoli, onion leaves, carrots, peppers, cabbages, apple skins, etc [36]. It is highly added as a food supplement due to its anti-oxidative property. Various pre-clinical reports have proven that Luteolin possesses a wide range of pharmacological activities like anti- hepatotoxic [37], hypotensive [38], anti-urolithiasis [39], haemostatic [40], antimicrobial or antibacterial activity [41], and many others. It is seen that the Luteolin has preventive activity against several parasitic agents like Leishmania Donovani [42] and plasmodium falciparum [43]. Many studies have been already done considering Luteolin as a potential inhibitor against the $\mathrm{M}^{\text {pro }}$ protease of COVID-19 [44]. The structure of Luteolin is downloaded from the online database "PubChem" (https://pubchem.ncbi.nlm.nih.gov/) ID:5280445) (Figure1).

\subsection{Computational method for structural analysis}

The ground state energy optimization is done with the help of the software "Gaussian 09" and method B3LYP with a standard 6-311G basis set. Optimized geometry is used to derive the Mulliken charge distribution and molecular electrostatic potential (MEP) surface map that helps in explaining the chemical stability of the molecule. The frontier molecular orbitals (FMO) (highest occupied molecular orbital and lowest unoccupied molecular orbital) energies are also derived with the help of optimized geometry. These HOMO-LUMO energies are used for computing ionization potential (IP), energy gap $(\Delta E)$, electron affinity $(E A)$, chemical potential $(C P)$, electronegativity $(\mathrm{X})$, softness $(\mathrm{S})$, and hardness $(\mathrm{\eta})$ [45]. These parameters are considered global reactivity parameters and help in determining the chemical reactivity of the molecule.

\subsection{Drug-likeness and ADMET properties}

We have done the virtual screening of drug-likeness rules and ADMET properties of Luteolin. Lipinski's rule, MDDR-like rule, Veber's s rule, Ghose filter, Egan rule, Muegge rule, lipophilicity, water-solubility, etc., are examples of drug-likeness rules [46]. Some of the drug-likeness rules are molecular weight $<500$, hydrogen bond donors $<5$, hydrogen bond acceptor $<10$, MLOGP ( -octanol-water partition coefficient) $<4.15$, molar refractivity should be between 40 and 130, $\log P$ ranging between -0.4 to +5.6 , solubility $(\log S)>-5.7$ [47]. Additionally, Absorption, Distribution, Metabolism, Excretion, and Toxicity (ADMET) properties are also important in drug designing as they signify whether the compound undergoes proper metabolic processes in the human body or is toxic [48]. In the present work, all the drug-likeness and ADMET features are listed with the help of the online database SwissADME.

\subsection{Prediction of activity spectra for substances (PASS)}

Cytotoxicity prediction is done with the help of the freely accessible online platform CLC-Pred (Cell Line Cytotoxicity Predictor) [49]. CLC-Pred is a cytotoxicity predictor used in in-silico studies that can predict the cytotoxic effect of chemical compounds by the virtue of PASS technology. Near about 4000 kinds of biological activities like toxic and adverse effects, mechanisms of action, interaction with metabolic enzymes and transporters, pharmacological effects influence on gene expression, etc. can be predicted by PASS [50]. The structure of Luteolin is submitted in smiles format. Prediction of the activity spectrum of a compound is estimated in terms of probable activity $(\mathrm{Pa})$ and probable inactivity $(\mathrm{Pi})$. $\mathrm{Pa}$ and $\mathrm{Pi}$ values vary between 0.000 and 1.000 [51]. The activities following condition $\mathrm{Pa}>\mathrm{Pi}$ are considered as possible for a particular compound. Experimental pharmacological action is considered high if the $\mathrm{Pa}>0.7$ and low if $0.5<\mathrm{Pa}<0.7$ [52]. Data can also be extracted in structured data file format. Analysis of data extracted from CLC-Pred is interpreted based on their IG50 (half-maximal inhibitory growth), IC50 (half maximal inhibitory concentration), and \% inhibition (of 
activity) values [53]. Compounds having IG50 and IC50 values $10000 \mathrm{nM}$ and inhibition of more than $50 \%$ are considered as active [54].

\subsection{Prediction of cardiac toxicity}

Prediction of cardiac toxicity detects the cardio-related harms by the consumption of the drug. Pred-hERG 4.2 is a freely accessible validated web server that is used for the identification of cardiotoxic blockers of the compound [55]. The human ether-a-go-go-related gene (hERG) is a cardiac repolarizer that mainly encodes a protein and also activates the rectifier potassium channel ( $\mathrm{IKr}$ ) [56]. Heartbeat delay is the main caution of dysfunctioning of hERG which may often cause sudden death [57]. The structure of Luteolin is submitted to Pred-hERG in smileys format. Potency, confidence, applicability domain, and probability map are recorded as the results [58]. To be non-cardio toxic, the confidence value should not exceed 0.26 for any compound. [59]. The fragments representing hERG blockage are indicated in the probability map.

\subsection{Molecular docking study}

For molecular docking studies, Chain 4 and Chain 7 are chosen based on the AGS cocrystal found naturally in the CryoEM structure of human MCM7 structure (PDB ID: 6XTX) [60]. Missing residues in Chain 4 and 7 structures are completed using SWISS-MODEL (https://swissmodel.expasy.org/). Based on the cocrystal AGS in the 6LXT structure, the active site coordinates are determined as x:211.170, y:201.937, and z:140.544, and the grid box volume is chosen as $20 * 20 * 20 \AA^{3}$. Molecular docking is performed with both Autodock Vina and Glide to validate the results $[61,62]$. The optimized Luteolin structure for molecular docking studies is obtained from the DFT study. The protein and ligand input pdbqt files required for Autodock Vina docking are created with AutoDockTools-1.5.6. For Glide docking, the protein structure is prepared with the 'Protein Preparation Wizard' in Schrödinger Maestro 12.8 and the ligand structure is prepared with the 'LigPrep' module using OPLS4 force field. Protein-ligand interactions are visualized using BIOVIA Discovery Studio Visualizer v21 and UCSF Chimera v1.15 software. The docked structure by Glide of Luteolin with chain 7 and chain 4 of 6 XTX is further used for performing MD simulations.

\subsection{Molecular dynamics simulations}

The software "Gromacs 2019.2 version" is used for performing the molecular dynamics simulation $[63,64]$. The protein preparation topology is created with Gromos 43A1 force field and SCP water model. The ligand topology file is obtained from the GlycoBioChem PRODRG2 server (http://davapc1.bioch.dundee.ac.uk/cgi-bin/prodrg) [65]. The protein-ligand complex is simulated for 300 ps in canonical (amount of substance (N), pressure (P) and temperature (T) - NVT) and 300 ps isothermal-isobaric (amount of substance (N), volume (V), and equilibrium steps temperature (T) - NPT) ensembles. The molecular dynamics simulations run for $100 \mathrm{~ns}$. The root mean square deviation (RMSD) and root mean square fluctuation (RMSF) is calculated to study the stability of the complex during the simulation. RMSD and RMSF help in the prediction of the atomic positions and the complex stability of the molecule undergoing simulation.

\section{Results And Discussions}

\subsection{Analysis of structural properties}




\subsubsection{Optimized structure and charge analysis}

The optimized geometry of Luteolin seems to be planar with the total electrostatic potential energy of -1028.92 au, and dipole moment 4.85 Debye. The high dipole moment of the probe molecule suggests the bioactivity of the structure that strengthens the formation of the bond between the drug and targeted protein [66]. Bond length $(\AA)$ and bond angle $\left(^{\circ}\right)$ between different atoms of optimized geometry are mentioned in SD.1 and SD.2.

The graphical representation of Mulliken charges shows the positive impact of hydrogen atoms and the negative impact of carbon and oxygen atoms (Figure 2(b)). Atom 50 bonded to benzene ring shows the maximum negative charge of $0.664 \mathrm{e} .60$ and 40 also show near about maximum negative charges of $0.609 \mathrm{e}$ and $0.614 \mathrm{e}$ respectively (SD.3). On the other hand, $22 \mathrm{H}, 28 \mathrm{H}, 29 \mathrm{H}$, and $31 \mathrm{H}$ are the hydrogen atoms showing the highest positive charges of $0.396 \mathrm{e}, 0.381 \mathrm{e} 0.396 \mathrm{e}$, and $0.400 \mathrm{e}$ respectively (SD 3). A high variation of charge within the molecule is observed for $\mathrm{C}$ atoms. High positive and negative effect in atoms shows the possibility of intramolecular charge transfer property within the Luteolin.

\subsubsection{Frontier molecular orbital (FMO) analysis}

The chemical reactivity, stability, and optical properties of a molecule are derived by HOMO (Highest occupied molecular orbital) and LUMO (Lowest unoccupied molecular orbital) energies. Koopman's theorem is used for calculating different FMO related parameters.

$I P=-E$ HOMO

$E A=-E_{L U M O}$

$C P=\frac{E_{\text {HOMO }}+E_{\text {LUMO }}}{2}$

$\chi=\frac{(I P+E A)}{2}$

$\eta=\frac{E_{\text {LUMO }}-E_{\text {HOMO }}}{2}, \quad S=\frac{1}{\eta}$ 
Table 1

Chemical parameters of Luteolin (All values are in $\mathrm{eV}$ and $\mathrm{S}$ is in $\left.(\mathrm{eV})^{-1}\right)$.

\begin{tabular}{|c|c|c|}
\hline S No. & Molecular property & Values \\
\hline 1. & HOMO & -6.32 \\
\hline 2. & LUMO & -2.35 \\
\hline 3. & Energy gap $(\Delta \mathrm{E})$ & 3.97 \\
\hline 4. & Ionization potential (IP) & 6.32 \\
\hline 5. & Electron affinity (EA) & 2.35 \\
\hline 6. & Chemical potential (CP) & -4.33 \\
\hline 7. & Electronegativity $(x)$ & 4.33 \\
\hline 8. & Hardness ( $(\eta)$ & 1.98 \\
\hline 9. & Softness (S) & 0.50 \\
\hline
\end{tabular}

The energy gap between the HOMO and LUMO energies is found to be 3.97eV. This confirms the delocalization of electrons within the molecule. The value of IP $(6.32 \mathrm{eV})$ shows the tendency of the molecule to easily loose the free electrons. The value of EA $(2.35 \mathrm{eV})$ is reported for the molecule that shows the atoms attract the electrons more easily. The value of $\chi$ is calculated to be $4.33 \mathrm{eV}$. All the FMO parameters confirm the high chemical reactivity of the Luteolin molecule. The high value of $\eta(1.986 \mathrm{eV})$ and low value of $\mathrm{S}(0.503 \mathrm{eV})$ shows the stability of the molecule. These parameters show the chemical reactivity of the system.

\subsubsection{MEP analysis}

The reactivity of any molecule is determined by examining the molecular electrostatic potentiality of the molecule. MEP helps in the determination of active sites of the molecule. Figure 4 shows the MEP surface indicating electrophilic regions from blue color and nucleophilic regions in yellow color. There is some portion of the molecule which is neutral or doesn't participate in the chemical reaction. In the MEP surface, the greencolored region shows the neutral part of the molecule. The electron-rich locations shaded in yellow color indicate that the molecule has plenty of electrons for undergoing chemical reactions and the maximum negative region for electrophile attack shown in blue color validates the possibility of the molecule being highly chemically reactive [67].

\subsection{Analysis of Drug likeness and ADMET properties}

Luteolin follows Lipinski's rule of five without any violation with a molecular mass of $286.24 \mathrm{~g} / \mathrm{mol}, \operatorname{log~p~}<5, \mathrm{H}$ donor<5, and $\mathrm{H}$-acceptor<10. Along with showing high gastrointestinal absorption and moderate solubility, Ghose's filter, Egan's rule, Veber's rule, and Mugge's rule. Table 2. Lists the properties and their responses for Luteolin. Lipophilicity or partition coefficient which is an important virtue of virtual screening which accounts for the affinity of the drug in the lipid environment. For a compound to be used as a drug lipophilicity value should be positive to be stable in lipid medium and log $\mathrm{p}$ should be less than 5 to be a potential drug. For Luteolin, all log $\mathrm{P}$ parameters are less than 5. Also, Luteolin has shown positive behavior for being water-soluble. Luteolin 
also shows high gastronomical intestinal absorption which shows it can be a better drug for human consumption. 
Table 2

Physiochemical, drug-likeness, pharmacokinetics, lipophilicity, and medicinal chemistry of Luteolin.

\begin{tabular}{|c|c|}
\hline \multicolumn{2}{|c|}{ Physicochemical Properties } \\
\hline Formula & $\mathrm{C}_{15} \mathrm{H}_{10} \mathrm{O}_{6}$ \\
\hline Molecular weight & $286.24 \mathrm{~g} / \mathrm{mol}$ \\
\hline Num. H-bond acceptors & 6 \\
\hline Num. H-bond donors & 4 \\
\hline Molar Refractivity & 76.01 \\
\hline TPSA & $111.13 \AA^{2}$ \\
\hline \multicolumn{2}{|l|}{ Lipophilicity } \\
\hline $\log P_{\mathrm{o} / \mathrm{w}}(\mathrm{iLOGP})$ & 1.86 \\
\hline $\log P_{\mathrm{o} / \mathrm{w}}(\mathrm{XLOGP3})$ & 2.53 \\
\hline $\log P_{\mathrm{o} / \mathrm{w}}(\mathrm{WLOGP})$ & 2.28 \\
\hline $\log P_{\mathrm{o} / \mathrm{w}}(\mathrm{MLOGP})$ & -0.03 \\
\hline $\log P_{\mathrm{o} / \mathrm{w}}($ SILICOS-IT) & 2.03 \\
\hline Consensus Log $P_{\mathrm{o} / \mathrm{w}}$ & 1.73 \\
\hline \multicolumn{2}{|l|}{ Water Solubility } \\
\hline $\log S(E S O L)$ & -3.71 \\
\hline Solubility & $5.63 \mathrm{e}-02 \mathrm{mg} / \mathrm{ml} ; 1.97 \times 10^{-4} \mathrm{~mol} / \mathrm{l}$ \\
\hline Class & Soluble \\
\hline $\log S$ (Ali) & -4.51 \\
\hline Solubility & $8.84 \mathrm{e}-03 \mathrm{mg} / \mathrm{ml} ; 3.09 \times 10^{-5} \mathrm{~mol} / \mathrm{l}$ \\
\hline Class & Moderately soluble \\
\hline $\log S($ SILICOS-IT) & -3.82 \\
\hline Solubility & $4.29 \mathrm{e}-02 \mathrm{mg} / \mathrm{ml} ; 1.50 \times 10^{-4} \mathrm{~mol} / \mathrm{l}$ \\
\hline Class & Soluble \\
\hline \multicolumn{2}{|l|}{ Pharmacokinetics } \\
\hline GI absorption & High \\
\hline BBB permeant & No \\
\hline
\end{tabular}




\begin{tabular}{|ll|}
\hline \multicolumn{2}{|l|}{ Physicochemical Properties } \\
\hline P-gp substrate & No \\
\hline Log $K_{\mathrm{p}}$ (skin permeation) & $-6.25 \mathrm{~cm} / \mathrm{s}$ \\
\hline Druglikeness & \\
\hline Lipinski & Yes; 0 violation \\
\hline Ghose & Yes \\
\hline Veber & Yes \\
\hline Egan & Yes \\
\hline Muegge & Yes \\
\hline Bioavailability Score & 0.55 \\
\hline Medicinal Chemistry & \\
\hline PAINS & 1 alert: catechol_A \\
\hline Brenk & 1 alert: catechol \\
\hline Leadlikeness & Yes \\
\hline Synthetic accessibility & 3.02 \\
\hline
\end{tabular}

\subsection{PASS analysis}

The considered molecule Luteolin is widely preferred for the treatment of hypertension, inflammatory disorders, and cancer. Data given in SD.4 displays one of the Breast carcinomas for $\mathrm{Pa}>0.3$ which matches with one of its known therapeutic applications. Cytotoxicity against many cell lines is also predicted including

Oligodendroglioma, Colon adenocarcinoma, Hepatoblastoma, and many more (SD.4). For Pa $>0.5$, cancer line Hs 683 (Oligodendroglioma), is predicted.

Predicted activity $(\mathrm{Pa})$ with value 0.523 and probable inactivity $(\mathrm{Pi})$ with value 0.049 is obtained for Luteolin. Results verify that the probable activity $(\mathrm{Pa})$ score is very close to 1 and the probable inactivity $(\mathrm{Pi})$ score is very close to 0 . Half maximal inhibitory concentration (IC50) which shows the extend of inhibiting of any compound against a specific biological function, shows more than $50 \%$ probability in Luteolin which is considered as an active compound. Figure 5 shows the percent share of possible biological activities possessed by Luteolin. Cancer cell growth anti-proliferation is explained as GI50 activity.

\subsection{Cardiac toxicity analysis}

The value of the applicability domain for Luteolin is observed to be 0.19 which lies in the acceptable range (less than 0.26$)$. The probability map shown in Figure 6 indicates the presence of both positive and negative contributions of atoms or fragments to the hERG blockage. From Figure 6, it is noticeable that the pink-colored region near the $\mathrm{OH}$ groups in the probability map indicates the decreased $\mathrm{hERG}$ blockage region. The set of atoms constituting oxygen promotes the hERG cardiac potentiality of the molecule. The low value of the applicability domain predicted Luteolin as non-cardiotoxic with a 50\% confidence value. 


\subsection{Molecular docking analysis}

After performing multiple times docking of the ligand with protein the first binding pose is considered as the best binding pose with binding affinity $-8.4 \mathrm{kcal} / \mathrm{mol}$ and four hydrogen bonds (Figure 7). All the conventional hydrogen bonds interaction details are mentioned in Table 4 with common active site amino acid residues GIn512, Ser509, Thr508, and Lys510. All these results show the first docked pose is the best pose of Luteolin in the binding site of MCM7. It also validates the potentiality of Luteolin to be used as a drug against MCM7 cancer. 2D structure of donor-acceptor interactions is also verified to locate the hydrogen bonds associated with the complex (Figure 7).

The docking results obtained by Schrodinger software are shown in Figure 8. The Glide XP score of -10 or less is considered as the good binding score. In case the hydrophobic interactions are associated with the binding site, the Glide XP score of -8 or -9 is also considered as the good binding score. In our case, the Glide XP score obtained by the docking of Luteolin with MCM7 has the value of -8.516 which is very close. The amino acid residues Glu420, Gln512, Tyr652, and Tyr465 are associated with conventional bond formation. The pi-sigma interaction is represented by Leu565 residue. Leu564, Leu660, Ala560, and Alg561 residues are associated with the pi-alkyl bond. The pose with glide emodel value -66.445 is selected as the best pose. Molecular interaction details obtained from Glide XP and Autodock Vina tools are given in Table 3.

Table.3 Luteolin molecular interaction details at the active site of MCM7 protein obtained from Glide XP and Autodock Vina tools 


\begin{tabular}{|c|c|c|c|c|}
\hline Protein/Docking Tools & $\begin{array}{l}\text { Interacting } \\
\text { residues }\end{array}$ & $\begin{array}{l}\text { Distance } \\
(\AA)\end{array}$ & Category & Type \\
\hline $\begin{array}{l}\text { DNA replication licensing factor MCM7 } \\
\text { (PDB ID: } 6 \text { XTX) }\end{array}$ & 4:Tyr465 & 2,23237 & $\begin{array}{l}\text { Hydrogen } \\
\text { Bond }\end{array}$ & $\begin{array}{l}\text { Conventional } \\
\text { Hydrogen Bond }\end{array}$ \\
\hline \multirow{11}{*}{$\begin{array}{l}\text { Glide XP } \\
(-8.5 \mathrm{kcal} / \mathrm{mol})\end{array}$} & 4:Gln512 & 2,12171 & & $\begin{array}{l}\text { Conventional } \\
\text { Hydrogen Bond }\end{array}$ \\
\hline & 4:Tyr652 & 2,0905 & & $\begin{array}{l}\text { Conventional } \\
\text { Hydrogen Bond }\end{array}$ \\
\hline & 7:Glu420 & 1,70975 & & $\begin{array}{l}\text { Conventional } \\
\text { Hydrogen Bond }\end{array}$ \\
\hline & 4:Leu656 & 2,93413 & Hydrophobic & Pi-Sigma \\
\hline & 4:Thr508 & 5,03603 & & Amide-Pi Stacked \\
\hline & 4:Ser509 & 4,2699 & & Amide-Pi Stacked \\
\hline & 4:Leu660 & 5,06686 & & Pi-Alkyl \\
\hline & 7:Ala560 & 4,91514 & & Pi-Alkyl \\
\hline & 7:Ala560 & 4,90091 & & Pi-Alkyl \\
\hline & 7:Arg561 & 5,05345 & & Pi-Alkyl \\
\hline & 7:Leu564 & 5,16814 & & Pi-Alkyl \\
\hline $\begin{array}{l}\text { DNA replication licensing factor MCM7 } \\
\text { (PDB ID: } 6 \text { XTX) }\end{array}$ & 4:Thr508 & 2,27927 & $\begin{array}{l}\text { Hydrogen } \\
\text { Bond }\end{array}$ & $\begin{array}{l}\text { Conventional } \\
\text { Hydrogen Bond }\end{array}$ \\
\hline \multirow{6}{*}{$\begin{array}{l}\text { Autodock Vina } \\
(-8.4 \mathrm{kcal} / \mathrm{mol})\end{array}$} & 4:Ser509 & 2,64023 & & $\begin{array}{l}\text { Conventional } \\
\text { Hydrogen Bond }\end{array}$ \\
\hline & 4:Lys510 & 2,40961 & & $\begin{array}{l}\text { Conventional } \\
\text { Hydrogen Bond }\end{array}$ \\
\hline & 4:Gln512 & 1,83235 & & $\begin{array}{l}\text { Conventional } \\
\text { Hydrogen Bond }\end{array}$ \\
\hline & 7:Arg561 & 3,88199 & Electrostatic & Pi-Cation \\
\hline & 7:Glu420 & 4,24757 & & Pi-Anion \\
\hline & 4:Lys510 & 5,14426 & Hydrophobic & Pi-Alkyl \\
\hline
\end{tabular}

\subsection{Molecular dynamics simulations}

\subsubsection{Root mean square deviation (RMSD)}

The RMSD is calculated to determine the protein-ligand stability and functionality of the complex. This provides an idea about the structural deviation of the protein-ligan complex during the time trajectory of 100ns (Figure 9). The RMSD deviation of Luteolin gave a rise up to $0.2 \mathrm{~nm}$ in the initial 10 seconds and remained constant for the whole simulation time. Unlike Luteolin, the RMSD of the apoprotein rise for initial 45 seconds of the simulation time. This rise in RMSD value increases up to $1 \mathrm{~nm}$ and fluctuates from $0.6 \mathrm{~nm}$ to $1 \mathrm{~nm}$ for the next 55 seconds. 
RMSD graph of MCM7-Luteolin complex shows intermediate values of apoprotein graph and Luteolin graph. The RMSD value of the complex fluctuates from $0.2 \mathrm{~nm}$ to $0.6 \mathrm{~nm}$ consistently. The consistent value of RMSD for complex shows that the complex remains stable during the whole simulation time.

\subsubsection{Root mean square fluctuations (RMSF)}

The RMSF gives insights into the protein residue fluctuations for the complex. The RMSF plot for chain 4 and chain 7 of the 6XTX protein complexed with Luteolin is analyzed for $100 \mathrm{~ns}$ of the simulation time. The RMSF plot of the complex is shown by red color and apoprotein is shown by black color (Figure 10). The plot for both the chains shows frequent fluctuations that validate the high flexibility of the complex. The plot indicates that the binding of the complex did not get affected throughout the simulation time. Thus, the RMSF analysis validates that the process of simulation did not alter the complex resulting in the stable protein-ligand complex.

\section{Conclusion}

This study has utilized comprehensive in-silico techniques for determining the anti-cancerous activity of Luteolin. The high value of the dipole moment of the Luteolin implies the bioactivity of the molecule. Therefore, it can better support the bond formation between the drug and targeted protein. Results of charge analysis show the property of charge transfer of the compound. FMO parameters like $\triangle E, I P, E A, C P$, and $\chi$ shows values favorable enough to ideally justifies its chemical stability. The high value of $\eta$ and the low value of $S$ shows the stiffness and the stability of the molecule. The presence of electrophilic and nucleophilic regions justifies the displacement of the electron cloud and hence intermolecular charge transfer within the Luteolin molecule. Throughout the virtual screening of pharmacokinetic properties like Lipinski rules, Ghose's filter, Egan's rule, Veber's rule, and Mugge's rule, etc, Luteolin proved itself a beneficial compound that shows druglike behavior. Along with showing positive results in ADMET properties, it responded to PASS and cardio-toxic analysis positively. The value of active probability for biological activities is much higher than the inactive probability that validates the probability of biological activities within the molecule. 0.19 is the value for the applicability domain is which is much less than 0.26 which is considered the cut-off value for cardio-toxicity. Thus, Luteolin does not have any cardio-toxic behavior and can be preferred as a potential drug against MCM7 cancer. Furthermore, the results of molecular docking revealed the binding score of the best binding site is found to be $-8.4 \mathrm{kcal} / \mathrm{mol}$ which is quite good. The RMSD and RMSF values obtained by MD simulations have proved that the selection of docking pose seems to be correct. The protein ligand complex maintains stability throughout the simulation time. Summarizing all the in-silico study results, direct towards the strong candidature of Luteolin as a potential inhibitor. We believe that our present study would provide a lead in drug development from Luteolin for preventing DNA

\section{Declarations}

\section{Funding}

No funding

Conflict of interest: 
The authors declare that they have no known competing financial interests or personal relationships that could have appeared to influence the work reported in this paper.

\section{Availability of data and material}

Protein structure: https://www.rcsb.org/

Ligand structure: https://pubchem.ncbi.nIm.nih.gov/

ADMET properties: http://www.swissadme.ch/

Molecular docking: https://swissmodel.expasy.org/

Docking analysis: https://disCover.3ds.com/discovery-studio-visualizer-download

Ligand topology: http://davapc1.bioch.dundee.ac.uk/cgi-bin/prodrg

\section{Author's contribution}

Shradha Lakhera: Data curation, Writing- Original draft preparation, Visualization, Investigation, Software, Validation.

Meenakshi Rana: Conceptualization, Methodology, Writing- Reviewing and Editing, Supervision

Kamal Devlal: Conceptualization, Writing- Reviewing and Editing

Ismail Celik: Software, Validation, Reviewing and Editing

Rohitash Yadav: Data curation, Software, Validation

\section{Acknowledgments}

The authors thank Ankara University-Scientific Research Unit for supplying the Schöridenger software program purchased under grant project number BAP-21B0237004. Molecular dynamics simulations reported were performed utilizing TÜBITAK (The Scientific and Technological Research Council of Turkey), ULAKBIM (The Turkish Academic Network and Information Center), and High Performance and Grid Computing Center (TRUBA resources).

\section{References}

1. S. P. Gupta, Quantitative structure- Activity Relationship Studies on Anticancer drugs, Chem. Rev. 94 (1994)1507-1551. https://doi.org/10.1021/cr00030a003

2. J. Fu, B. Zhou, L. Zhang, K. S. Balaji, C. Wei, X. Liu, H. Chen, J. Peng, J. Fu, Expressions and significances of the angiotensin-converting enzyme 2 gene, the receptor of SARS-CoV-2 for COVID-19, Mol. Biol. Rep. 47 (2020) 4383-4392. https://doi.org/10.1007/s11033-020-05478-4

3. World Health Organisation health report on Cancer 2018. https://www.who.int/healthtopics/cancer\#: :text=Cancer\%20is\%20the\%20second\%20leading,in\%20six\%20deaths\%2C\%20in\%202018. 
4. IARC- GLOBOCAN 2020: New Global Cancer Data. https://www.uicc.org/news/globocan-2020-new-globalcancer-

data\#: :text=IARC\%20released\%20on\%2014th\%20December,million\%20cancer\%20deaths\%20in\%202020.

5. M. Nugent, MicroRNA function and dysregulation in bone tumors: the evidence to date. Cancer. Manag. Res. 6 (2014) 15-25. https://doi.org/10.2147/CMAR.S53928

6. Y. Liu, T. A. Richards, S. J. Aves, Ancient diversification of eukaryotic MCM DNA replication proteins. BMC. Evol. Biol 9 (2009). https://doi.org/10.1186/1471-2148-9-60

7. C. Hua, G. Zhao, Y. Li, L. Bie, Minichromosome Maintenance (MCM) Family as potential diagnostic and prognostic tumor markers for human gliomas. BMC Cancer. 14 (2014) 526. https://doi.org/10.1186/14712407-14-526

8. O. Hyrien, How MCM loading and spreading specify eukaryotic DNA replication initiation sites. F1000Research. 5 (2016) 2063. https://doi.org/10.12688/f1000research.9008.1

9. D. Boos, J. Frigola, J. F. X. Diffley, Activation of the replicative DNA helicase: breaking up is hard to do, Curr. Opin. Cell Biol. 24 (2012)423-430, https://doi.org/10.1016/j.ceb.2012.01.011.

10. S. Donovan, J. Harwood, L. S. Drury, J. F. X. Diffley, Cdc6p-dependent loading of Mcm proteins onto prereplicative chromatin in budding yeast, PNAS. 94 (1997) 5611-5616.

https://doi.org/10.1073/pnas.94.11.5611

11. A. R. Leman, E. Noguchi, The Replication Fork: Understanding the Eukaryotic Replication Machinery and the Challenges to Genome Duplication, Genes. 4 (2013) 1-32. https://doi.org/10.3390/genes4010001

12. C. Petropoulou, P. Kotantaki, D. Karamitros, S. Taraviras, Cdt1 and Geminin in cancer: markers or triggers of malignant transformation, Front. Biosci. 13 (2008) 4485-4494. https://doi.org/10.2741/3018

13. S. Sen, R. Chakraborty, B. De, Challenges and opportunities in the advancement of herbal medicine: India's position and role in a global context, J. Herb. Med. 1 (2011)67-75, https://doi.org/10.1016/j.hermed.2011.11.001

14. S. Lakhera, K. Devlal, A. Ghosh, M. Rana, In Silico Investigation of Phytoconstituents of Medicinal Herb Piper Longum Against SARS-CoV-2 by Molecular Docking and Molecular Dynamics Analysis, Results in Chemistry (2021)100199. https://doi.org/10.1016/j.rechem.2021.100199

15. U. Matulonis, A. Sood, L. Fallowfield, Ovarian cancer, Nat. Rev. Dis. Primers. 2 (2016) 16061. https://doi.org/10.1038/nrdp.2016.61

16. Z. Duan, B. Wei, J. Deng, Y. Mi, Y. Dong, C. Zhu, R. Fu, L. Qu, D. Fan, The anti-tumor effect of ginsenoside Rh4 in MCF-7 breast cancer cells in vitro and in vivo, Biochem. Biophys. Res. Commun. 499 (2018) 482487. https://doi.org/10.1016/j.bbrc.2018.03.174

17. S. Sadeghi, A. Davoodvandi, M. H. Pourhanifeh, N. Sharifi, R. A. Nezhad, R. Sahebnasagh, S. A. Moghadam, A. Sahebkar, H. Mirzaei, Anti-cancer effects of cinnamon: Insights into its apoptosis effects, Eur. J. Med. Chem. 178 (2019) 131-140. https://doi.org/10.1016/j.ejmech.2019.05.067

18. S. Ambulkar, P. Ambulkar, M. P. Deshmukh, A. B. Budhrani, Experimental Evaluation of Wound Healing Activity of Various Dosage Forms of Tridax Procumbens, Indian J. Forensic Med. Toxicol. 14 (2020).

19. Y. Andriana, T. D. Xuan, T. N. Quy, T. N. Minh, T. M. Van, T. D. Viet, Antihyperuricemia, Antioxidant, and Antibacterial Activities of Tridax procumbens L." Foods 8 (2019) 1-21. https://doi.org/10.3390/foods8010021 
20. V.M. Berlin Grace, S. Viswanathan, D David Wilson, et al, Significant action of Tridax procumbens L. leaf extract on reducing the TNF- $a$ and COX-2 gene expressions in induced inflammation site in Swiss albino mice. Inflammopharmacol 28, (2020) 929-938. https://doi.org/10.1007/s10787-019-00634-0

21. V. Bhagat, M. Kondawar, ANTITUBERCULAR POTENTIAL OF DENDROPHTHOE FALCATE (L.) AND TRIDAX PROCUMBENS (L.) PLANTS EXTRACTS AGAINST H37Rv STAIN OF MYCOBACTERIA TUBERCULOSIS, Int. J. Pharm. Sci. Res. 10 (2019) 251-259. https://doi.org/10.13040/IJPSR.0975-8232.10(1).251-59

22. V. Ravikumar, K. S. Shivashangari, T. Devaki, Hepatoprotective activity of Tridax procumbens against dgalactosamine/lipopolysaccharide-induced hepatitis in rats, J. Ethnopharmacol.101(2005) 55-60. https://doi.org/10.1016/j.jep.2005.03.019

23. V. C. Bhagat, M. S. Kondawar, A comprehensive review on phytochemistry and pharmacological use of Tridax procumbens Linn. J. pharmacogn. phytochem. 8 (2019) 01-10

24. J. Ikewuchi, Effect of aqueous extract of Tridax procumbens Linn on plasma electrolytes of salt loaded rats, Pakistan. J. Nutr. 9 (2010) 103-105

25. R. Sujitha, R. Sharmila, PHYTOCHEMICAL ANALYSIS AND IN VITRO ANTICANCER ACTIVITY OF TRIDAX PROCUMBENS LINN, World J. Pharm. Res. 7 (2018) 867-878. https://doi.org/10.20959/wjpr201810-12319

26. Y. Qiu, W. Wang, B. Zhang, L. Mei, Z. Shi, MCM7 amplification and overexpression promote cell proliferation, colony formation and migration in esophageal squamous cell carcinoma by activating the AKT1/mTOR signaling pathway, Oncol. Rep. 37 (2017) 3590-3596. https://doi.org/10.3892/or.2017.5614

27. P. Barik, P. Talukdar, ESTABLISHED PHYTOLIGANDS FROM TRIDAX PROCUMBENS LINN. AGAINST BACTERIAL DNA-GYRASE B RECEPTOR: MOLECULAR DOCKING APPROACH, World J. Pharm. Res. 7 (2018). https://doi.org/10.20959/wjpr201812-12576

28. M. Imran, A. Rauf, T. A. Izneid, M. Nadeem, M. A. Shariati, I. A. Khan, A. Imran, I. E. Orhan, M. Rizwan, M. Atif, T. A. Gondal, M. S. Mubarak, Luteolin, a flavonoid, as an anticancer agent: A review, Biomed. Pharmacother. 112 (2019)108612. https://doi.org/10.1016/j.biopha.2019.108612

29. Q. Yu, M. Zhang, Q. Ying, Decrease of AIM2 mediated by luteolin contributes to non-small cell lung cancer treatment, Cell Death Dis 10 (2019) 218. https://doi.org/10.1038/s41419-019-1447-y

30. R. G. Closas, C. A. Gonzalez, A. Agudo, E. Riboli, Intake of specific carotenoids and flavonoids and the risk of gastric cancer in Spain. Cancer Causes Control 10 (1999) 71-75. https://doi.org/10.1023/A:1008867108960

31. M. Rana, A. Jain, V. Rani, P. Chowdhury, Glutathione capped core/shell CdSeS/ZnS quantum dots as a medical imaging tool for cancer cells, Inorg. Chem. Commun. 112 (2020) 107723. https://doi.org/10.1016/j.inoche.2019.107723

32. J. Fang, Q. Zhou, X. I. Shi, B. H. Jiang, Luteolin inhibits insulin-like growth factor 1 receptor signaling in prostate cancer cells, Carcinogenesis. 28 (2007) 713-723. https://doi.org/10.1093/carcin/bgl189

33. S. A. Ganai, F. A. Sheikh, Z. A. Baba, M. A. Mir, M. A. Mantoo, M. A. Yatoo, Anticancer activity of the plant flavonoid luteolin against preclinical models of various cancers and insights on different signalling mechanisms modulated, Phytother. Res. 35 (2021) 3509-3532. https://doi.org/10.1002/ptr.7044

34. M, Horinaka, T. Yoshida, T. Shiraishi, S. Nakata, M. Wakada, R. Nakanishi, H. Nishino, T. Sakai, The combination of TRAIL and luteolin enhances apoptosis in human cervical cancer HeLa cells, Biochem. Biophys. Res. Commun. 333 (2005) 833-838. https://doi.org/10.1016/j.bbrc.2005.05.179. 
35. S. Byun, K. W. Lee, S. K. Jung, E. J. Lee, M. K. Hwang, S. H. Lim, A. M. Bode, H. J. Lee, Z. Dong, Luteolin Inhibits Protein Kinase $\mathrm{C} \varepsilon$ and c-Src Activities and UVB-Induced Skin Cancer, Cancer. Res. 70 (2010). https://doi.org/10.1158/0008-5472.CAN-09-4093

36. R. Khajuria, S, Singh, A. Bahl, General Introduction and Sources of Flavonoids. In: Singh Tuli H. (eds) Current Aspects of Flavonoids: Their Role in Cancer Treatment, Springer, Singapore (2019). https://doi.org/10.1007/978-981-13-5874-6_1

37. S. Wagh, G. Shinde, Protective Effect of Tridax procumbens Linn Against Isoniazid Induced Hepatic Damage, J. Pharm. Res. 4 (2011) 3612-3614.

38. H.M. Salahdeen, O.K. Yemitan, A.R.A. Alada, Effect of aqueous leaf extract of tridax procumbens on blood pressure and heart rate in rats, Afr. J. Biomed. Res. 7 (2004). https://doi.org/10.4314/ajbr.v7i1.54062

39. D.B. Haytowitz, S. Bhagwat, J.M. Holden, Sources of Variability in the Flavonoid Content of Foods, Procedia Food Sci. 2 (2013) 46-51. https://doi.org/10.1016/j.profoo.2013.04.008.

40. Z. Lin, Y. Fang, A. Huang, L. Chen, S. Guo, J. Chen, Chemical constituents from Sedum aizoon and their hemostatic activity, Pharm. Biol. 52 (2014). https://doi.org/10.3109/13880209.2014.895019

41. J. Preveena, S. J. Bhore, Identification of bacterial endophytes associated with traditional medicinal plant Tridax procumbens Linn., Anc Sci Life. 32 (2013) 173-177. https://doi.org/10.4103/0257-7941.123002

42. G. A. G. Rebolledo, S. D. Jonas, M. A. J. Arellanes, Natural compounds and extracts from Mexican medicinal plants with anti-leishmaniasis activity: An update, Asian Pacific, J. Trop. Med, 10 (2017) 1105-1110. https://doi.org/10.1016/j.apjtm.2017.10.016.

43. P. Ghosh, S. Biswas, M. Biswas, A. Dutta, S. Sil, S. Chatterjee, Morphological, Ethno biological and Phytopharmacological Attributes of Tridax procumbensLinn. (Asteraceae): A Review, Int. j. sci. res. biol. sci. 6 (2019)182-191. https://doi.org/10.26438/ijsrbs/v6i2.182191

44. T. C. Theoharides COVID-19, pulmonary mast cells, cytokine storms, and beneficial actions of luteolin, Biofactors. 46 (2020) 306-308. https://doi.org/10.1002/biof.1633

45. P. Yadav, M. Rana, P. Chowdhury, DFT and MD simulation investigation of favipiravir as an emerging antiviral option against viral protease (3CLpro) of SARS-CoV-2, J. Mol. Struct. 1246 (2021)131253. https://doi.org/10.1016/j.molstruc.2021.131253

46. S. Deb, A. A. Reeves, R. Hopefl, R. Bejusca, ADME and Pharmacokinetic Properties of Remdesivir: Its Drug Interaction Potential. Pharmaceuticals. 14 (2021) 655. https://doi.org/10.3390/ph14070655

47. F. Cheng, W. Li, Y. Zhou, J. Shen, Z. Wu, G. Liu, P.W. Lee, Y. Tang, A Comprehensive Source and Free Tool for Assessment of Chemical ADMET Properties. ACS Publication Chem. Inf. Model. 52 (2012) 3099-3105. https://doi.org/10.1016/j.molstruc.2017.09.108

48. D. F. Veber, S. R. Johnson, H. Y. Cheng, B. R. Smith, K. W. Ward, K. D. Kopple, Molecular Properties That Influence the Oral Bioavailability of Drug Candidates, J. Med. Chem. 45(2002) 2615-2623. https://doi.org/10.1021/jm020017n

49. A.W. Schüttelkopf, D. M. van Aalten. PRODRG: a tool for high-throughput crystallography of protein-ligand complexes. Acta Crystallogr D Biol Crystallogr. 60 (2004) 1355-1363. https://doi.org/10.1107/S0907444904011679.

50. A. Lagunin, A. Stepanchikova, D. Filimonov, V. Poroikov, PASS: prediction of activity spectra for biologically active substances, Bioinformatics, 16 (2000) 747-748. https://doi.org/10.1093/bioinformatics/16.8.747 
51. S. Anzali, G. Barnickel, B. Cezanne, M. Krug, D. Filimonov, V. Poroikov, J. Med. Chem. 44 (2001) 2432-2437. https://doi.org/10.1021/jm0010670

52. P. Chinnasamy, R. Arumugam,In silico prediction of anticarcinogenic bioactivities of traditional antiinflammatory plants used by tribal healers in Sathyamangalam wildlife Sanctuary, India, EJBAS. 5 (2018)265-279. https://doi.org/10.1016/j.ejbas.2018.10.002.

53. A. Thomas, P. Peter, N. Chandramohanakumar, A Profiling of Anti-Tumour Potential of Sterols in the Mangrove Fern Acrostichum aureum, Int. J. Pharmacogn. Phytochem. Res. 8(2016) 1828-1832.

54. M. Nand, P. Maiti, R. Pant, M. Kumari, S. Chandra, V. Pande, Virtual screening of natural compounds as inhibitors of EGFR 696-1022 T790M associated with non-small cell lung cancer. Bioinformation. 12(2016) 311-317. https://doi.org/10.6026/97320630012311

55. R. C. Braga, V. M. Alves, M. F. Silva, E. Muratov, D. Fourches, L. M. Lião, A. Tropsha, C. H. Andrade, PredhERG: A Novel web- Accessible Computational Tool for Predicting Cardiac Toxicity. Mol Inform. 34(2015) 698-701. https://doi.org/10.1002/minf.201500040

56. H. M. Lee, M. S. Yu, S. R. Kazmi, Computational determination of hERG-related cardiotoxicity of drug candidates. BMC Bioinformatics. 20 (2019) 250. https://doi.org/10.1186/s12859-019-2814-5

57. J. F. Hong, O. Baghdad, J. S. Hwang, D. H. Uwe, In silico assessment of human health risks caused by cyanotoxins from cyanobacteria, Biocell, Mendoza, 45 (2021) 65-77.

https://doi.org/10.32604/biocell.2021.014154

58. A. A. Lagunin, V. I. Dubovskaja, A. V. Rudik, P. V. Pogodin, D. S. Druzhilovskiy, T. A. Gloriozova, CLC-Pred: A freely available web-service for in silico prediction of human cell line cytotoxicity for drug-like compounds. PLoS ONE 13 (2018) 0191838. https://doi.org/10.1371/journal.pone.0191838

59. R. C. Braga,V. M. Alves, M. F. B. Silva, E. Muratov, D. Fourches, L. M. Liao, A. Tropsha, C. H. Andrade, PredhERG: A Novel web-Accessible Computational Tool for Predicting Cardiac Toxicity, Mol Inform. 34 (2015) 698-701. https://doi.org/10.1002/minf.201500040

60. E. A. Perez, Cardiac Toxicity of ErbB2-Targeted Therapies: What Do We Know?, Clinical Breast Cancer, 8 (2008) S114-S120, https://doi.org/10.3816/CBC.2008.s.007

61. R. A. Friesner, R. B. Murphy, M. P. Repasky, L. L. Frye, J. R. Greenwood, T. A. Halgren, D. T. Mainz, Extra precision glide: Docking and scoring incorporating a model of hydrophobic enclosure for protein- ligand complexes. J. Med. Chem. 49 (2006) 6177-6196. <background-color:\#CFBFB1;uverticalalign:super;>https://doi.org/10.1021/jm0512560</background-color:\#CFBFB1;uvertical-align:super;>

62. O. Trott, A. J. Olson, AutoDock Vina: improving the speed and accuracy of docking with a new scoring function, efficient optimization, and multithreading, J. Comput. Chem. 31(2010) 455-461. https://doi.org/10.1002/jcc.21334

63. H. Bekker, H.J.C. Berendsen, E.J. Dijkstra, S. Achterop, R. van Drunen, D. van der Spoel, A. Sijbers, H. Keegstra, "Gromacs: A parallel computer for molecular dynamics simulations”, Physics computing. Edited by R.A. de Groot and J. Nadrchal. World Scientific, Singapore, 92 (1993) 252-256.

64. M. J. Abraham, T. Murtola, R. Schulz, S. Páll, J.C. Smith, B. Hess, E. Lindahl, "GROMACS: High performance molecular simulations through multi-level parallelism from laptops to supercomputers," SoftwareX, 1 (2015) 19-25. <background-color:\#CFBFB1;uvertical- 
align:super;>https://doi.org/10.1016/j.softx.2015.06.001</background-color:\#CFBFB1;uverticalalign:super;>

65. N. J. Rzechorzek, S. W. Hardwick, V. A. Jatikusumo, D. Y. Chirgadze, L. Pellegrini, CryoEM structures of human CMG-ATPYS-DNA and CMG-AND-1 complexes. Nucleic Acids Res. 48 (2020) 6980-6995. https://doi.org/10.1093/nar/gkaa429

66. M. Rana, P. Chowdhury,Nonlinear optical responses of organic based indole derivative: An experimental and computational study, Mater Today: Proc. 28 (2020)241-245. https://doi.org/10.1016/j.matpr.2020.01.598.

67. M. Rana, Pooja, P. Chowdhury, Investigation on nonlinear optical responses of different pyrrole derivatives: A computational study AIP. Conf. Proc. 2136 (2019) 040005. https://doi.org/10.1063/1.5120919

\section{Figures}
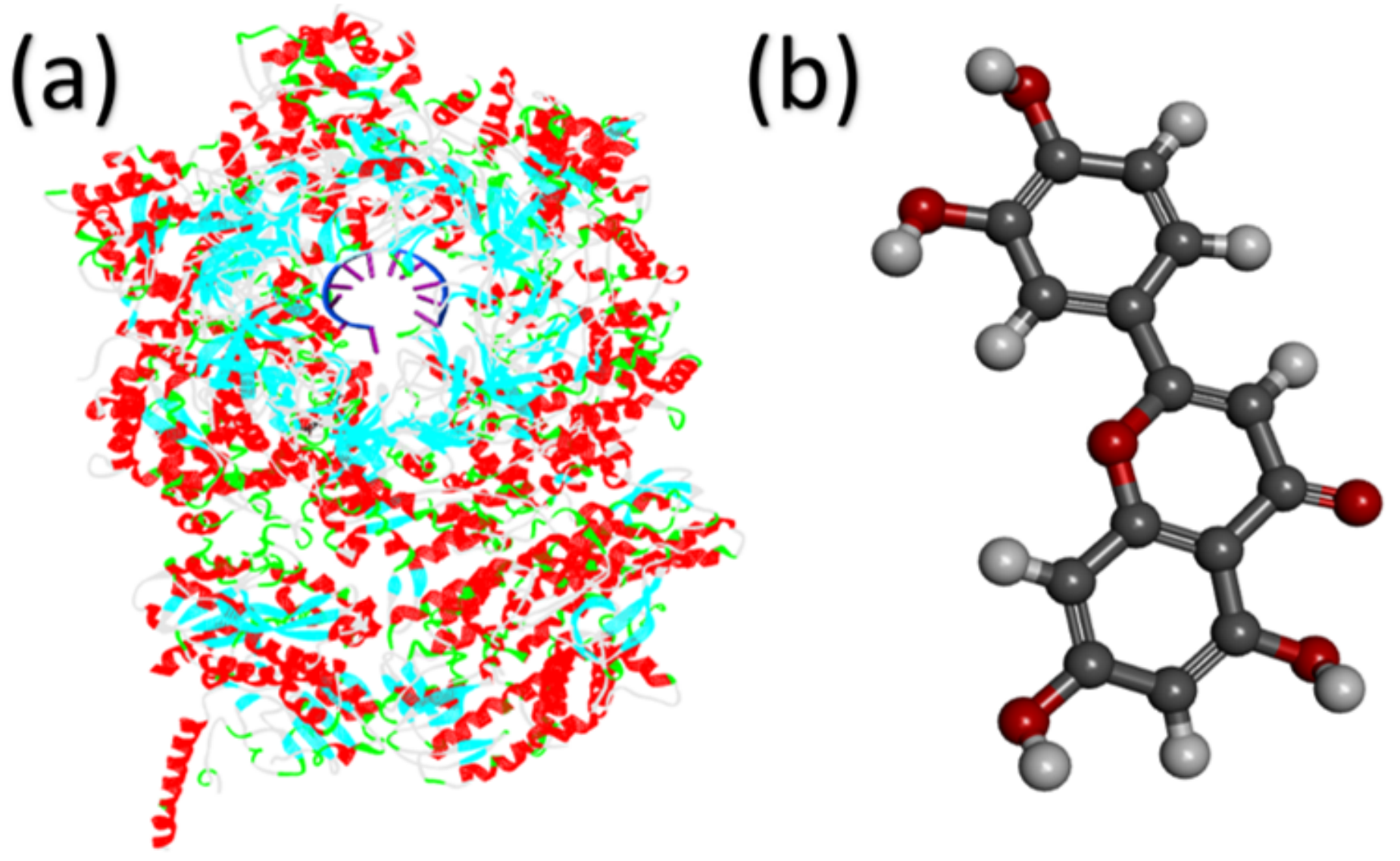

Figure 1

(a) Structure of receptor protease MCM7 (PDB ID: 6XTX) with DNA backbone and basic pairs are located at the center of the structure (Backbone: blue, Basic pairs: magenta), (b) Structure of Luteolin. 


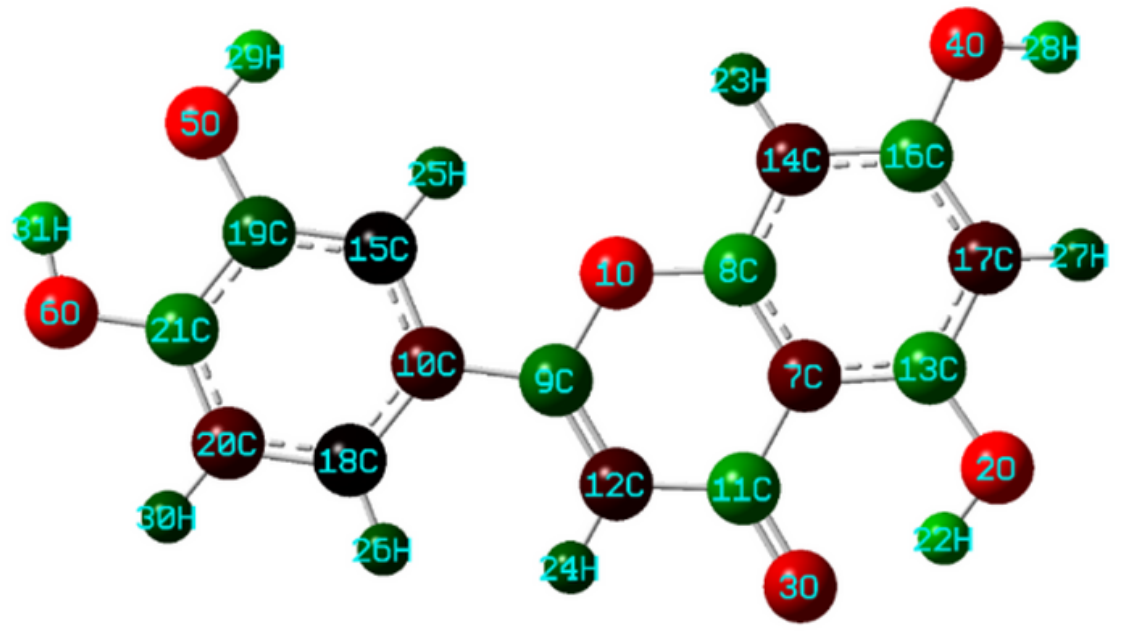

(a)

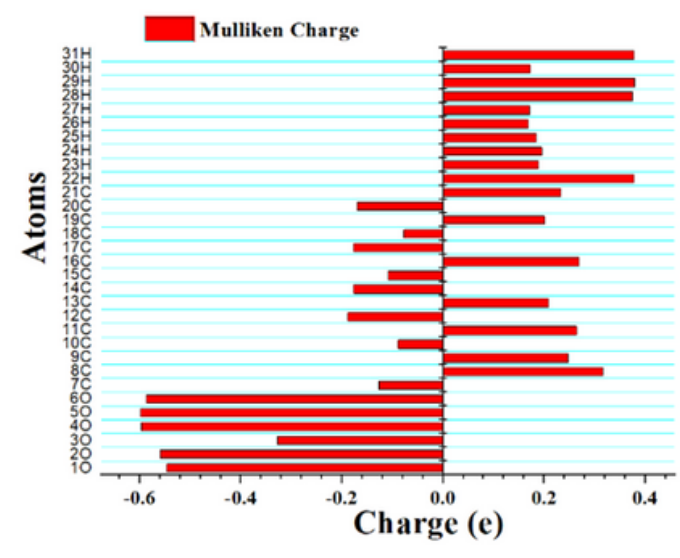

(b)

\section{Figure 2}

(a) Optimized structure of Luteolin. Red atoms are oxygen, dark green is hydrogen, light green is carbon, and brown are the carbons bonded to hydrogen. (b) Plot showing Mulliken charge distribution of Luteolin. The plot shows the positive behaviour of hydrogen and the negative behaviour of oxygen. 


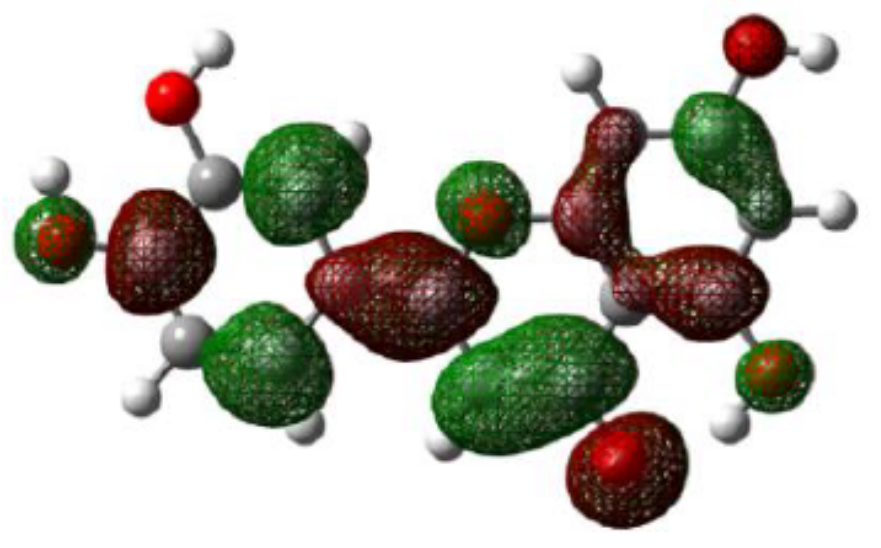

$$
\Delta \mathbf{E}=\mathbf{E}_{\mathrm{LUMO}}-\mathrm{E}_{\text {Hомо }}=3.97231 \mathrm{eV}
$$

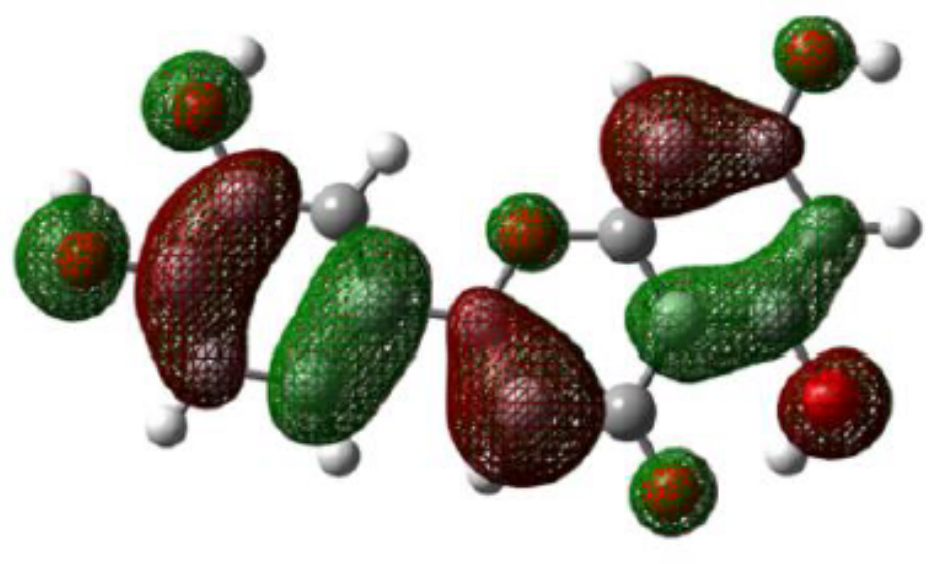

\section{LUMO \\ $-2.35160 \mathrm{eV}$}

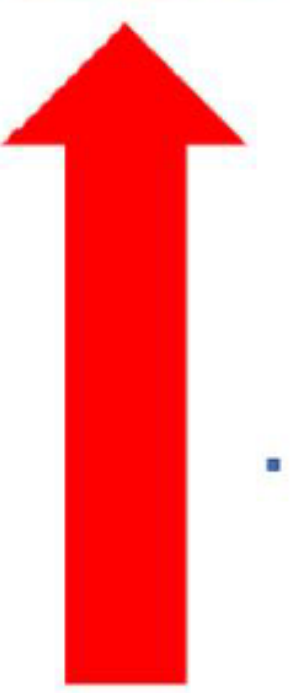

HOMO

$-6.32391 \mathrm{eV}$

Figure 3

HOMO and LUMO with respective energies and energy differences. 

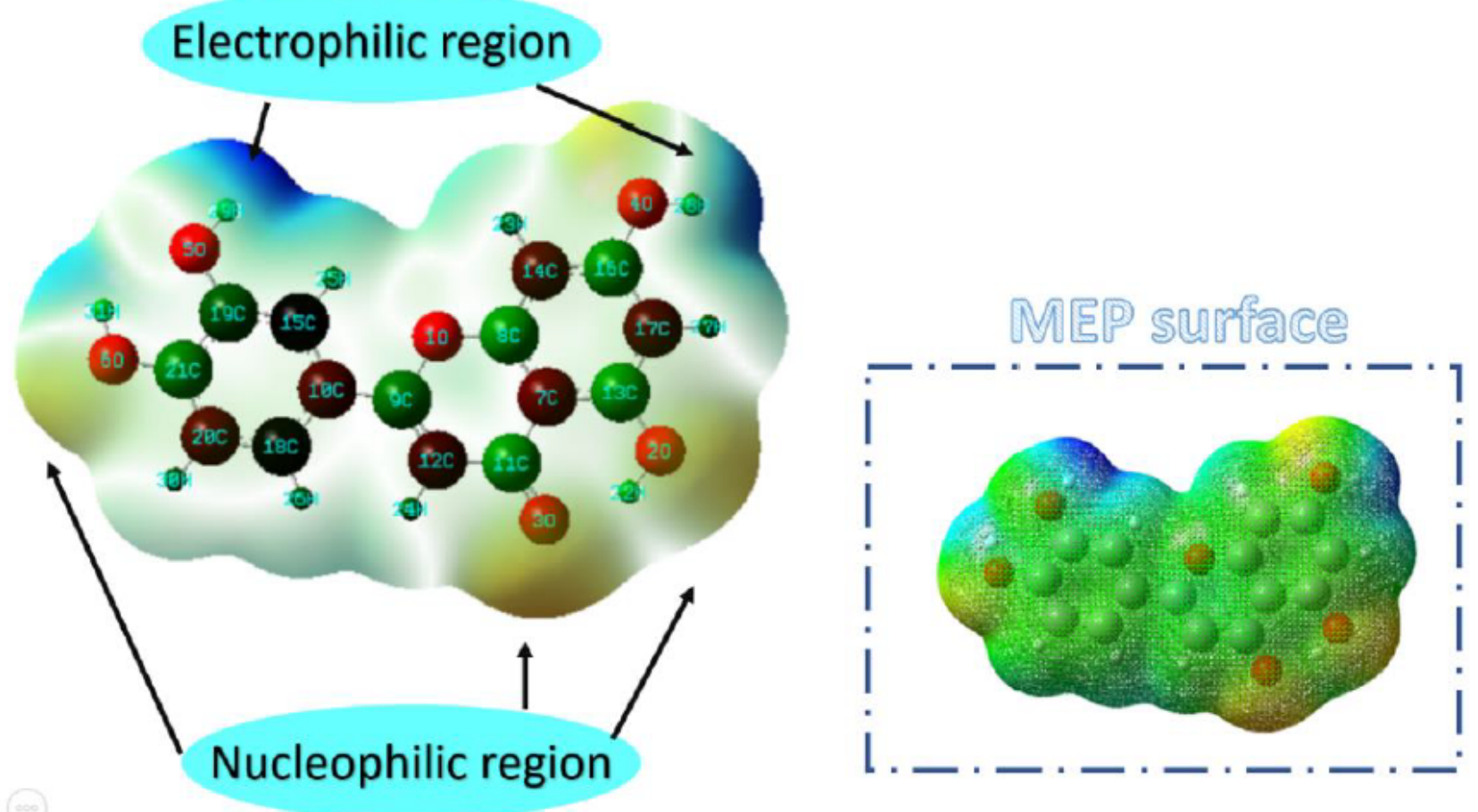

Figure 4

MEP surface showing the electrophilic region in blue colour and nucleophilic region in yellow portions. 


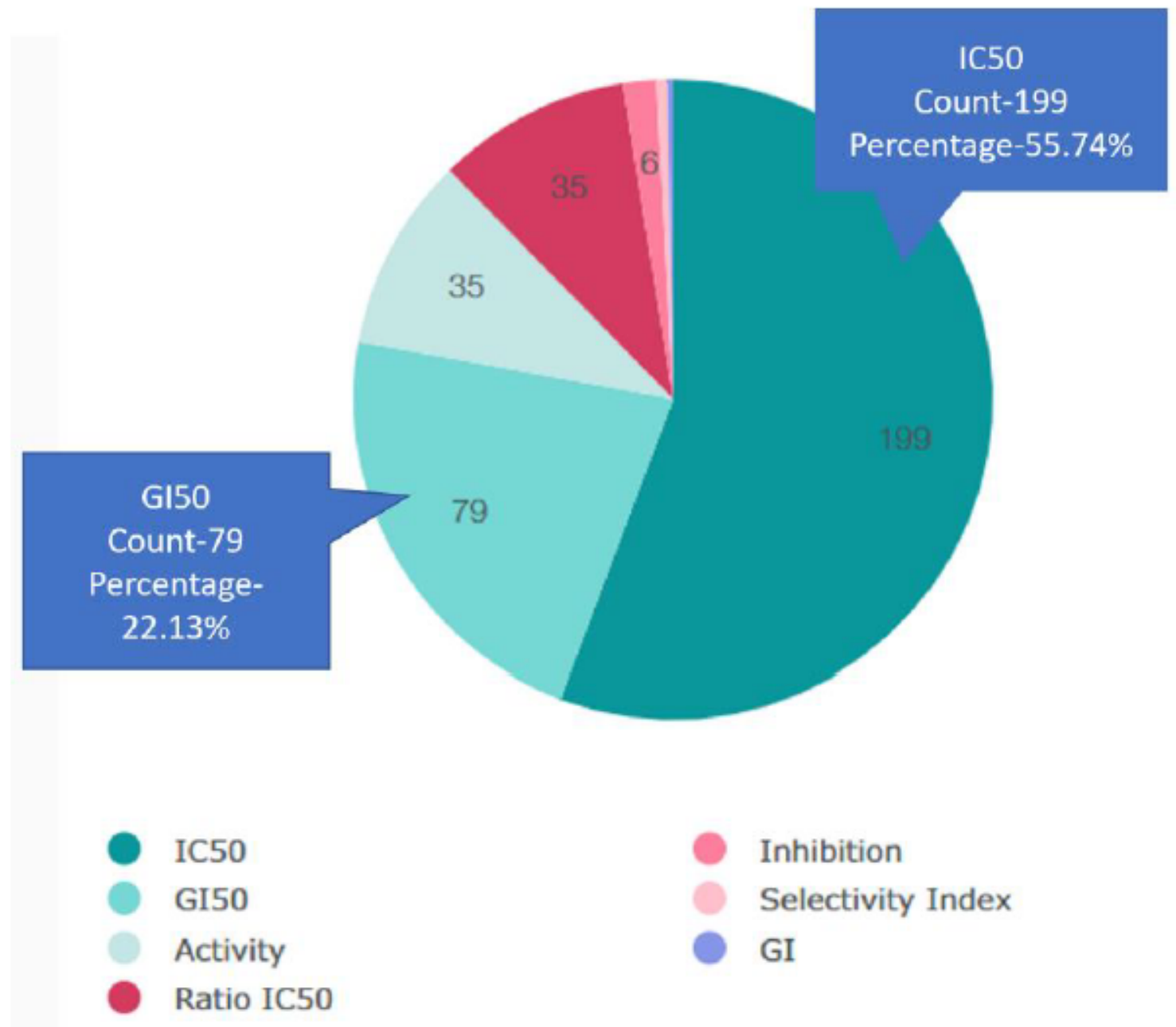

\section{Figure 5}

Pie chart showing types of possible biological activities in Luteolin. Share of IC50 and GI50 is also shown with probability percentage. 


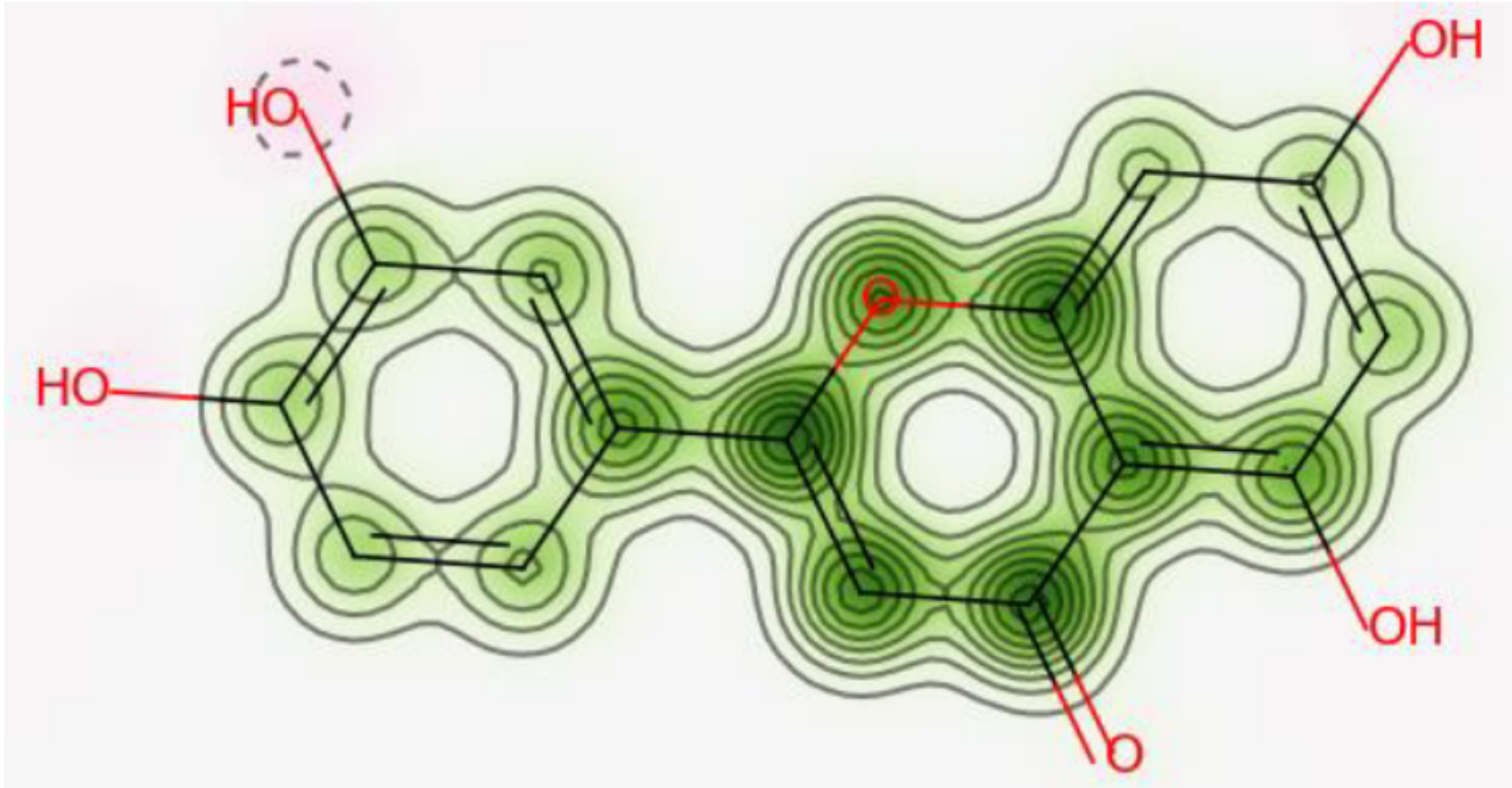

Figure 6

Probability map of Luteolin showing hERG blockage promoting regions in pink shade. 

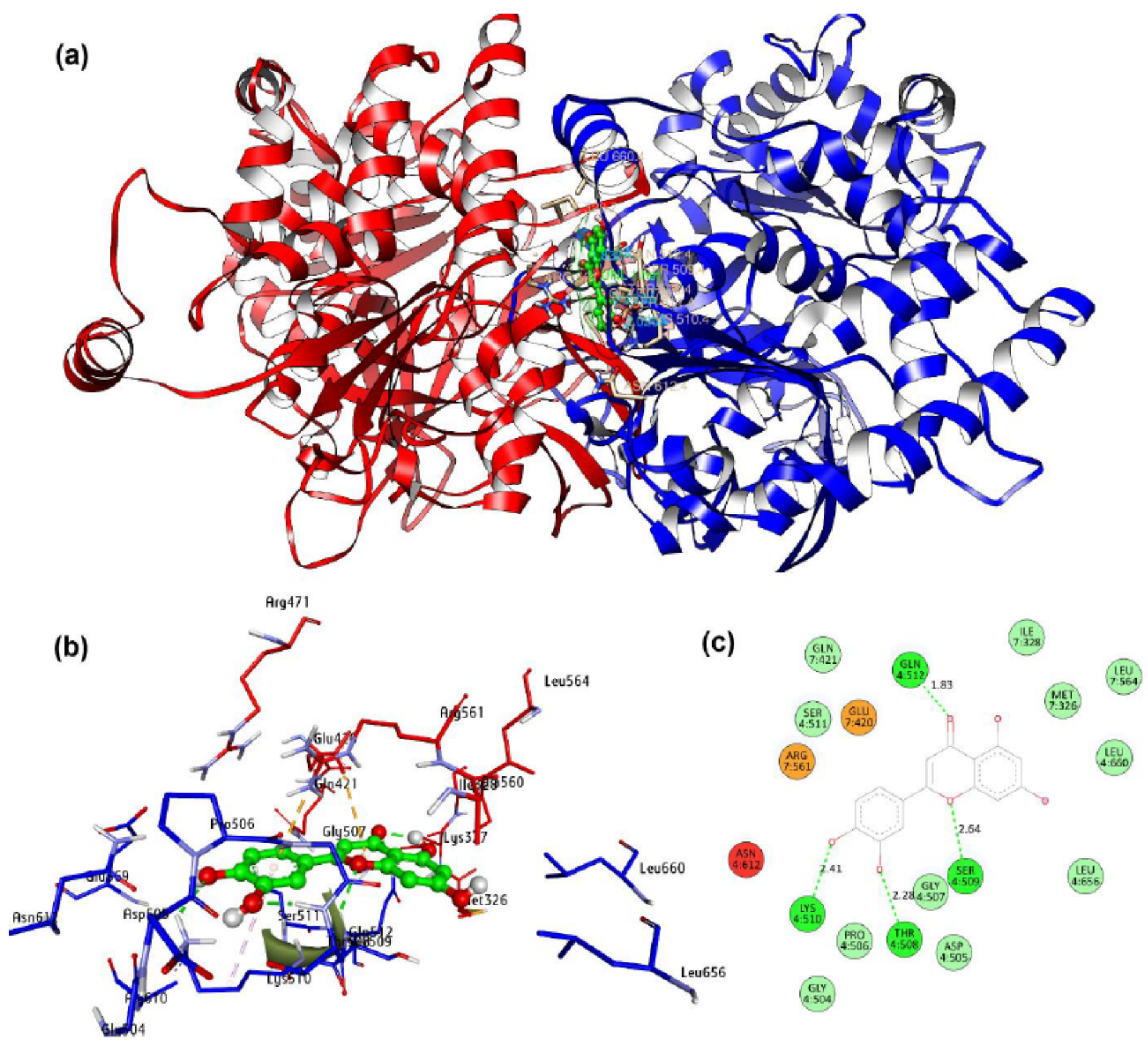

Figure 7

(a) 3D view of the whole protein and ligand obtained from Autodock Vina. (b) Molecular docking binding pose of chain 4 (blue), chain 7 (red) and luteolin (green) at MCM7 protein active site. (c) Schematic protein-ligand molecular interactions diagram including $\mathrm{H}$ bond lengths. 


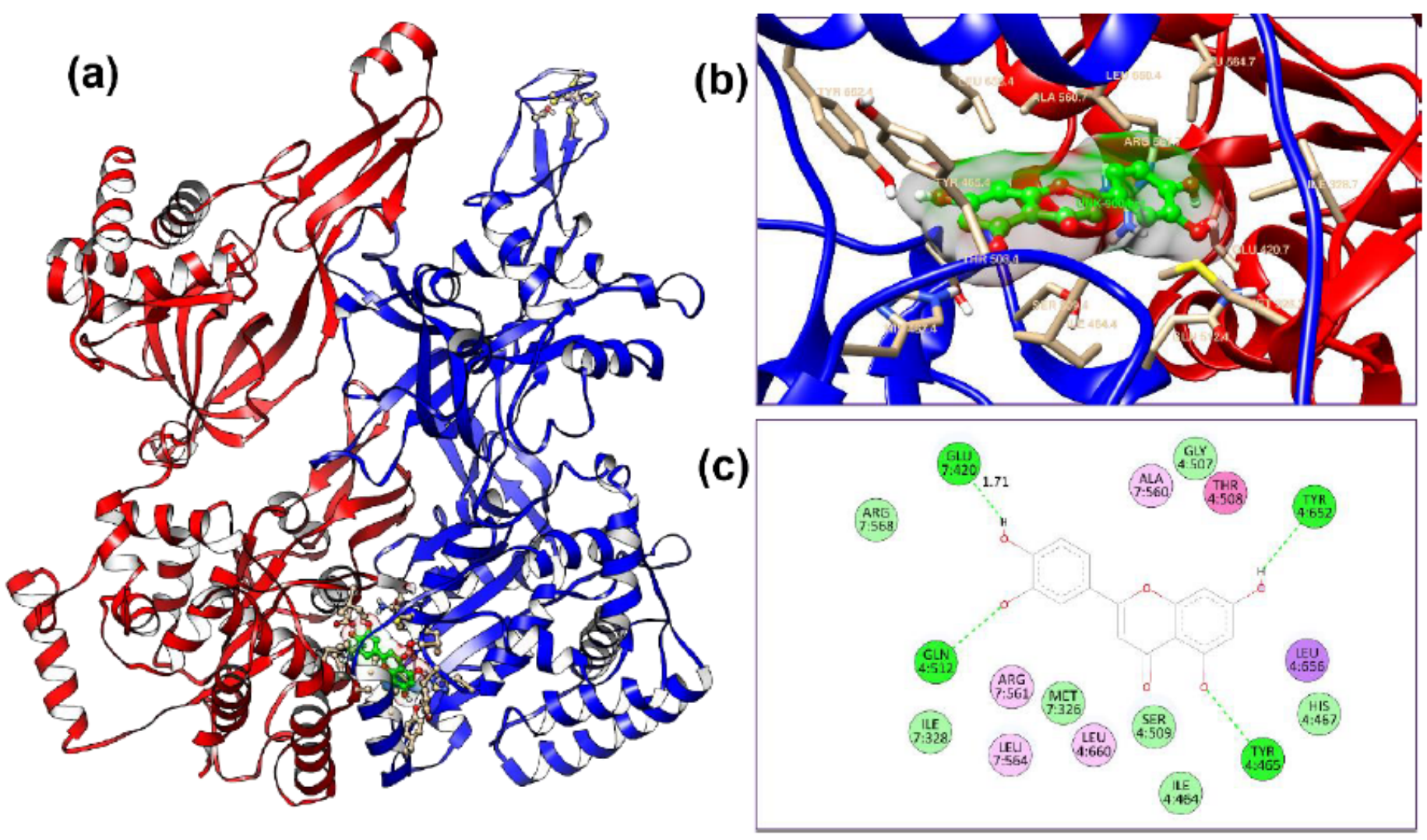

Figure 8

(a) Docking mode of protein and ligand by Schrodinger- Glide XP docking of protein active site with Chain 7 (red), and chain 4 (blue) with MCM7, (b) 3-D interaction of donor-acceptor interaction obtained by docking of Luteolin with MCM7, (c) 2-D view of protein-ligand interaction showing conventional, carbon and pi-donor $\mathrm{H}$ bonds.

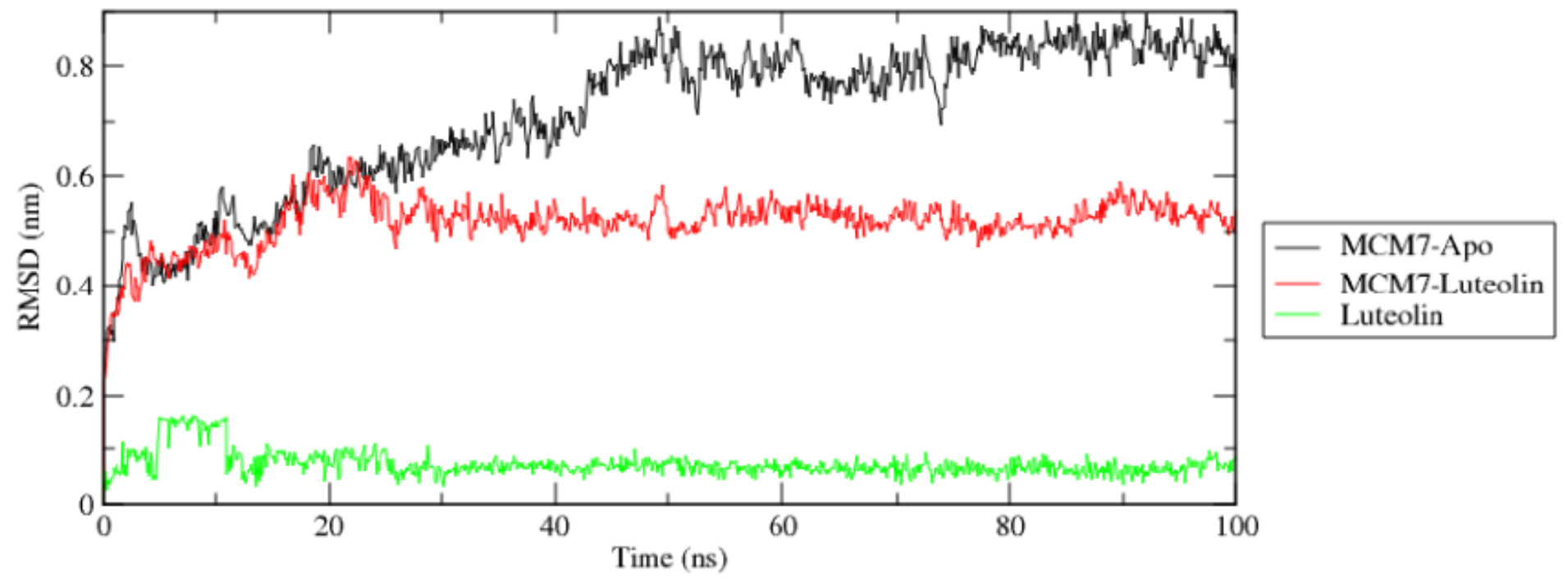

Figure 9 
Root mean square deviation (RMSD) of MCM7 apo protein and its complex with Luteolin for time trajectory from 0 ns to 100 ns.
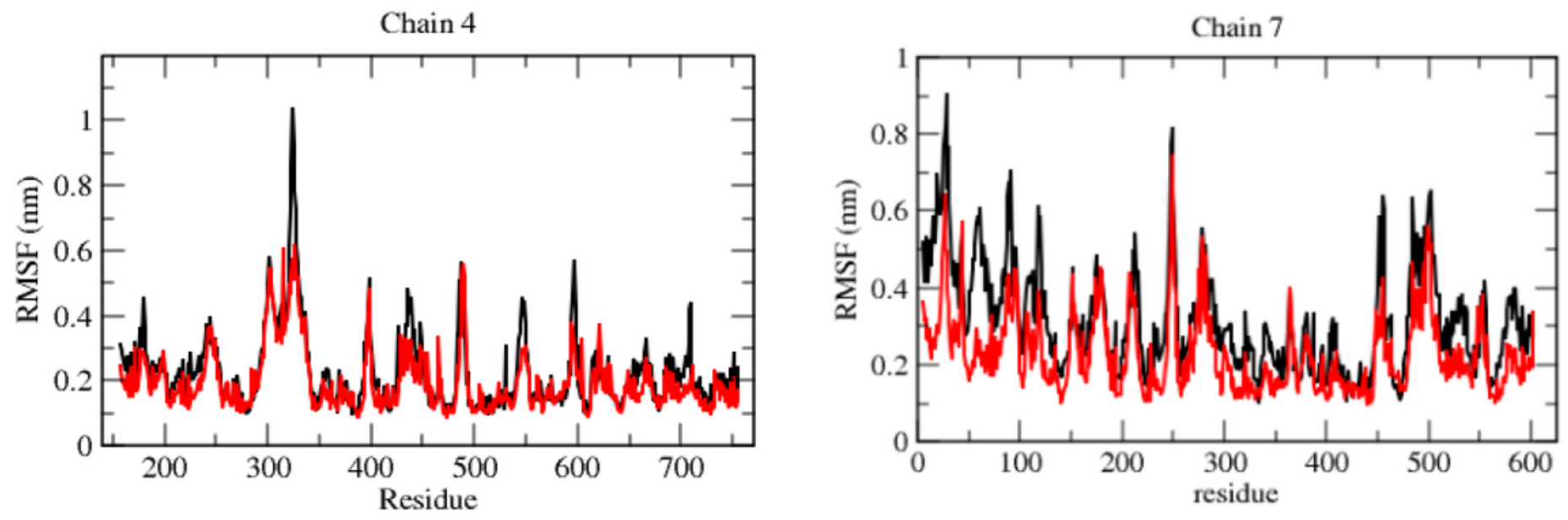

Figure 10

Root mean square fluctuations (RMSF) graph of MCM7 in apoprotein (black) and its complex (red) with Luteolin for chain 4 and chain 7 of the protein for time trajectory of 100ns.

\section{Supplementary Files}

This is a list of supplementary files associated with this preprint. Click to download.

- Graphicalabstract.pdf

- Supportingdocument.docx 